\title{
Necessity of Collaboration between Technology and Architectural Design in Order to Develop the Urban Space Quality
}

\author{
Mina Khodadad, Mohsen Sanei \\ Department of Architecture, Politecnico di Milano University, Milan, Italy \\ Email: mina.khodadad@mail.polimi.it
}

How to cite this paper: Khodadad, M. and Sanei, M. (2017) Necessity of Collaboration between Technology and Architectural Design in Order to Develop the Urban Space Quality. World Journal of Engineering and Technology, 5, 574-584.

https://doi.org/10.4236/wjet.2017.54049

Received: June 26, 2017

Accepted: September 18, 2017

Published: September 22, 2017

Copyright $\odot 2017$ by authors and Scientific Research Publishing Inc. This work is licensed under the Creative Commons Attribution International License (CC BY 4.0).

http://creativecommons.org/licenses/by/4.0/

c) (i) Open Access

\begin{abstract}
Proper architectural design and appropriate usage of technology compatible with the environment in parts of a city which is called urban spaces, spaces such as parks, squares, sidewalks, shopping malls, leave a great impact on the quality of the urban life. Architectural design itself is born from technology; it means that, architecture is tied with science and technology, and is in direct contact with them. Technological innovations are one of the most important forces affecting the architectural changes. Nowadays, technological innovations are recognized as important and effective powers in development of sustainable environmental design. Today societies are constantly changing in terms of social, economic, political and technological alterations. Change is inevitable, and like all aspects of contemporary life, architecture should similarly offer an appropriate response to such changes for remaining sustainable, useful and appropriate. Architecture should also have a suitable response to laws and regulations of recent issues like safety, environment and energy conservation, and even personal security in architectural space. The purpose of this paper is, primarily an exploration of the concept of "urban space", and in the second stage, it plans to review the fundamentals and impacts of using technology in urban spaces. The research method is descriptive-analytic and library research method is used for data collecting.
\end{abstract}

\section{Keywords}

Urban Space, Technological Innovations, Sustainable Environmental Design

\section{Introduction}

By looking at technology era, in the realm of urban space and social life, and 
thinking of positive and negative effects of technology in this field, we can reach the growing change in urban spaces and urban lives. This change introduces the element of technology, as a main force of shaping the space. Therefore the aim of this study-by using descriptive-analytic method and library research method for data collecting-is to investigate the interaction between technology and urban space. Technology products, which are imported in to the consumer markets every day, bring a new culture with themselves. Human as a consumer, accepts consumption of moral and material products of technology and, as a result, he knows himself dependent to it. Since urban space is a product of historical, social and cultural forces of the community, its character is not only caused by geographical, physical and civil conditions, but also due to the technological design. Therefore, it is necessary to understand the mechanism of technology in space. Urban Space is a social, cultural and physical issue, which depends on activity patterns of social groups, and is the product of cultural force, social force and correct application of technology. But these forces will lead to produce a technological urban space, only in case that civic space synchronization with science and technology is provided. This article, first, tries to express the concepts of "space" and "urban space" and the theoretical foundation of urban space. In the second phase, the concept of "technology" and its relation with architecture and urban development are studied. Some effective applied examples of using technology in urban developments are represented in next part. As results, some solutions for proper technological design in urban development are proposed.

\section{Concept of Space}

Space is not an obvious concept by itself, this concept has much wider meaning than a relatively simple definition of physical or natural place, which is implicitly arises in discussions and refers to three dimensions of the external world, to the frequency, separation and distance between people and objects, and between objects [1]. Space is created by a specific set of natural and artificial things, which architecture is involved in their creation [2]. Architectural space can be perceived objectively, be felt directly and be identified by its defining elements [3]. The relation between inside and outside, which is the first aspect of objective space, shows that spaces have various levels of extension and surrounding [4]. Space, is the time and place volume of a set of all activities, which human does it in order to survive and dominate the nature. In other words, it is an economic and social sphere that reflects all existence of a human society [5].

\section{Concept of Urban Space}

Urban space is the main place for events, which organizes a creative role in linking today with tomorrow. Urban space is a traffic location between present, past and future. This space contains four basic elements: Residents or passers-byes, Man-made elements (Physical or activity), Relationships (Among indi- 
viduals and elements or between elements), and Time [6]. Urban space is a common ground, where people do their functional activities and events, which are the links between the members of the community inside it, and is a scene, which displays the public life. Urban space is the place we share with strangers; people, who are not our relatives, friends or colleagues. It is a place for politics, religion, business and sports, a place for peaceful coexistence and non-personal encounters. In fact, urban spaces can be described equivalent to public spaces [7]. Urban public spaces play major roles in the real city life, from socio-economic issues to cultural and environmental matters [8].

\section{Theoretical Foundations of Urban Space}

Study of urban development history shows that the issue of urban space in ancient times, in the spatial organization of the city, was the outcome of political and social action in the public domain. Habermas, searches for public domains' historical and spatial roots inside the halls and general assemblies of public and free discussions in eighteenth century. This concept was changed from the late eighteenth, and with gaps in public life concept and outstrip of economic institutions from other institutions, the matter of separation of subject, object, form and function transformed the concept of urban space. In the twentieth century, with the Modern Movement (based on functionalism), zoning or disintegration of functions in the city to four fundamental actions and with the domination of the machine, urban space was practically forgotten. Since the sixties of the twentieth century, by the theory of culturists, urban space is counted as a part of a construction of a city, and have an integrated concept, which in terms of physical aspects, has an enclosed framework, and city activities are establishing there. Urban space, as a part of urban living organism, is associated with social and economic conditions, and possesses a social environment that involves relationships between people [9]. If we want to make the concept of urban space clear, without incurring aesthetic criteria, inevitably we have to call the spaces between buildings in cities and other places, urban space. Geometrically, this space is enclosed with various symbols. Only its clarity of geometric features and aesthetic qualities allows us to consciously consider the exterior open space as an urban space. Exterior open spaces are defined by divisions of public, semi-public and private, in order to move in fresh air [10]. Regarding the theoretical foundations of discussion, it can be said that a group of experts, such as Rob Krier, studied the urban space as a construction of a city, and a group of experts, like Camillo Sitte, investigated the subject from the field of aesthetics, and some like Giddens, reviewed urban space from the perspective of social ecology. The concept of urban space, in conceptual framework of social humanity purposes, is defined in compliance with human targets and social activities; and urban spaces, streets, squares become as tools to strengthen the spirit of public cooperation and interactions. The basic function of the city lies in the abundance of community activities and public areas, which are fields to display social life of individuals and social groups. Public space becomes the scene, in which actors and audiences 
change their role respectively [11]. Existence of sustainable public spaces in cities is essential to prevent and predict social harms in society, in order to reduce depression and violence [12].

\section{Concept of Technology}

Technology concept can be considered from different aspects and different approaches. Past researchers have viewed and defined the term "technology" from many perspectives and this has influenced the research design and results, negotiations around a transfer and government policies in general [13]. According to various aspects of science, philosophy, society, culture and even politics, technology becomes increasingly stronger and spreads more. Today philosophical approaches to technology become very important [14]. Philosophers, who first raised the philosophy of technology or somehow underlie these thoughts, were modern philosophers. Its context was created by Francis Bacon, Galileo and other Renaissance thinkers. Technology has a Greek origin and is composed of two words: Tekhne and Logia [15], Tekhne means art, craft and is something created by man, on the contrary, Arche means God created. "Logia" in ancient Greek is used in meaning of knowledge and wisdom. Thus we can say that technology is mixture of art and science skills. The word "technique" is a French word and it means, industry, science, art and profession.

\section{Technology and Architecture}

Architecture can be known as a combination of four main parts (Figure 1):

1) Form, means the geometry and shape of the work.

2) Function, includes land uses and enjoying the architectural space.

3) Culture and Content, a nonphysical context, which includes proposed concepts and definitions, in the parts and the entire work, which stems from culture, history, beliefs and philosophical foundations of society and the architect.

4) Technology, includes the constructing process, thinking about how to build together with materials, techniques and construction systems [16].

As it is shown in Table 1 using the technology and the amount of that subsequently, may differ in different species of architectural design, in terms of context.

\section{Technology in Urban Development}

Rogers believes that each building should reflect its own time. In the technological design of urban spaces it is observable that, by using the technology, architects try to use the maximum amount of natural elements, such as sunlight,

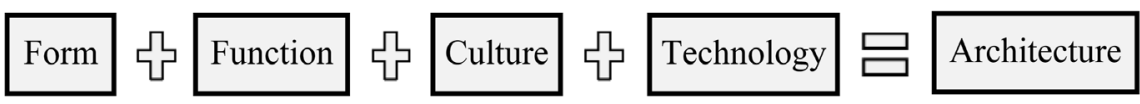

Figure 1. Architecture combination. 
Table 1. Different species of architectural design in context and the amount of adaptation to new technologies.

\begin{tabular}{|c|c|c|}
\hline $\begin{array}{l}\text { Type of architecture } \\
\text { in context }\end{array}$ & $\begin{array}{l}\text { Identifying features } \\
\text { and components }\end{array}$ & $\begin{array}{l}\text { The adaptation amount } \\
\text { by using the new } \\
\text { construction technologies }\end{array}$ \\
\hline $\begin{array}{c}\text { Totally } \\
\text { context-oriented }\end{array}$ & $\begin{array}{l}\text { The design is beyond its immediate } \\
\text { context and the effect of that is per- } \\
\text { ceivable beyond the scope of } \\
\text { existing contexts. Instead it creates } \\
\text { context for itself. It has played an } \\
\text { important role in the city's identity } \\
\text { and has very likely become an icon. }\end{array}$ & $\begin{array}{l}\text { Use of new technology only if } \\
\text { combined with existing fields. }\end{array}$ \\
\hline $\begin{array}{c}\text { Deeply } \\
\text { context-oriented }\end{array}$ & $\begin{array}{l}\text { Building design meets the } \\
\text { surrounding environment very } \\
\text { well, and is combined with the } \\
\text { environment without } \\
\text { any dissociation. }\end{array}$ & $\begin{array}{l}\text { Any kind of usage looks prohi- } \\
\text { bited, so we need } \\
\text { Non-Generalization Restoration } \\
\text { and Conservation Approaches } \\
\text { for the new built spaces. }\end{array}$ \\
\hline $\begin{array}{l}\text { Case between } \\
\text { two above situations }\end{array}$ & $\begin{array}{l}\text { At first glance, the building } \\
\text { represents a lot of attention } \\
\text { as a result of a great design } \\
\text { and is certainly an icon by itself. }\end{array}$ & $\begin{array}{l}\text { In case of non-iconic } \\
\text { orientation use of new } \\
\text { technology has no problem. }\end{array}$ \\
\hline $\begin{array}{c}\text { Totally } \\
\text { Non-context-oriented }\end{array}$ & $\begin{array}{l}\text { Building design has not any under- } \\
\text { standing of the context, } \\
\text { while it could not overcome it. } \\
\text { Finally, this type of buildings } \\
\text { can be seen in a bad way. }\end{array}$ & $\begin{array}{l}\text { The use of any new technology } \\
\text { construction is permitted, } \\
\text { because no solution could im- } \\
\text { prove the current situation. }\end{array}$ \\
\hline $\begin{array}{c}\text { successful } \\
\text { non-context-oriented }\end{array}$ & $\begin{array}{l}\text { Building protrudes like a wounded } \\
\text { finger, but the scheme of the } \\
\text { building defines architecture as a } \\
\text { creative person. This work is } \\
\text { usually intentional and planned. }\end{array}$ & $\begin{array}{l}\text { It is applicable Regarding } \\
\text { to the identity and } \\
\text { cultural context of the site } \\
\text { and the project area. }\end{array}$ \\
\hline $\begin{array}{c}\text { Unwanted } \\
\text { non-context oriented }\end{array}$ & $\begin{array}{l}\text { Architect's effort is to create an } \\
\text { architecture by paying attention } \\
\text { to the context and understanding } \\
\text { of the environment. But for some } \\
\text { reason he could not succeed. In- } \\
\text { cluding due to poor design, } \\
\text { defects in communication } \\
\text { with the environment } \\
\text { or a combination of both. }\end{array}$ & $\begin{array}{l}\text { Technology can use the } \\
\text { existing contexts of culture } \\
\text { and identity to reduce the } \\
\text { amount of unwanted } \\
\text { non-context-oriented design. }\end{array}$ \\
\hline $\begin{array}{l}\text { Obediently con- } \\
\text { text-oriented }\end{array}$ & $\begin{array}{l}\text { Building design reflects } \\
\text { environment and neighborhood } \\
\text { elements and buildings are } \\
\text { combined seamlessly with the } \\
\text { general view of the street. }\end{array}$ & $\begin{array}{l}\text { Must be coordinated with envi- } \\
\text { ronmental elements and neigh- } \\
\text { borhoods and only in this case, } \\
\text { technology can be used. }\end{array}$ \\
\hline $\begin{array}{c}\text { Stylistic } \\
\text { Context-oriented }\end{array}$ & $\begin{array}{l}\text { The design is such that makes } \\
\text { it context-oriented based on the } \\
\text { time period that it is made and also } \\
\text { according to the dominant style } \\
\text { that prevails the architecture } \\
\text { the context-oriented one. }\end{array}$ & $\begin{array}{l}\text { It is permitted in case of } \\
\text { being in harmony with the } \\
\text { style of architecture } \\
\text { and monuments and } \\
\text { the existing site. }\end{array}$ \\
\hline
\end{tabular}


wind, groundwater and plants, in order to regulate environmental conditions of spaces. Therefore sometimes the new architecture is called ECOTECHNOLOGY (Ecology + technology). Technology is not against nature, but it is beside and in parallel of nature, for further exploitation of environmental facilities and providing human comfort.

Urban development should be guided by a sustainable planning and management vision that promotes interconnected green space, a multi-modal transportation system, and mixed-use development. The combination of human scale urbanism, with a mixture of uses and services, a range of housing options, extensive train systems, and the ability to walk and bicycle as part of daily life, together could make the living process green, add the possibility of using clean and renewable energy, and have true sustainability results.

In the era of dwindling oil supplies and rising energy costs, the need for low energy lifestyles has never been greater than today. Urban design principles and practices bring together the ideas and plans to create enjoyable places to live, work and play while greatly reducing energy use.

\section{Use of Technology in Urban Space}

Proper and Eco technique design approaches, in parts of the city which are called urban spaces, spaces such as parks, some squares, sidewalks, shopping malls, leaves a great impact on the quality of urban life. New shape of today's urban spaces that fits our today needs, is not just because of a different design, but also the type of implementation and materials used in buildings have many influences in making different apparent of buildings. Our future living environment depends on issues, such as the use of technology in order to reduce the use of materials, increase sustainability and lifecycle and maximize the use of reversible and energy-saving products and materials. However, often we see that cities resist against technology like any new phenomenon, because they know it as an external and abuse phenomenon. As long as architects do not show the concept of technology within the urban, and they do not identify it in the city, and participation of citizens in these areas is not possible, this problem will remain. Therefore, the task of urban architecture is to internalize the phenomenon that has been conceived external and imposed.

\section{Examples of Technological Architecture Projects in Urban Spaces}

\subsection{Smog Free Tower in Beijing, China}

The [Smog Free] tower (Figure 2) is part of the Smog Free Project, a clean air initiative led by Dutch artist and designer Daan Roosegaarde, who bills the structure as "the largest electronic vacuum cleaner in the world." Stationed in parks, the tower creates a bubble of clean air in otherwise polluted areas. The exterior consists of 45 silver plates that resemble Venetian blinds housing a huge internal air purifier, which uses patented ion technology to make air up to 75 


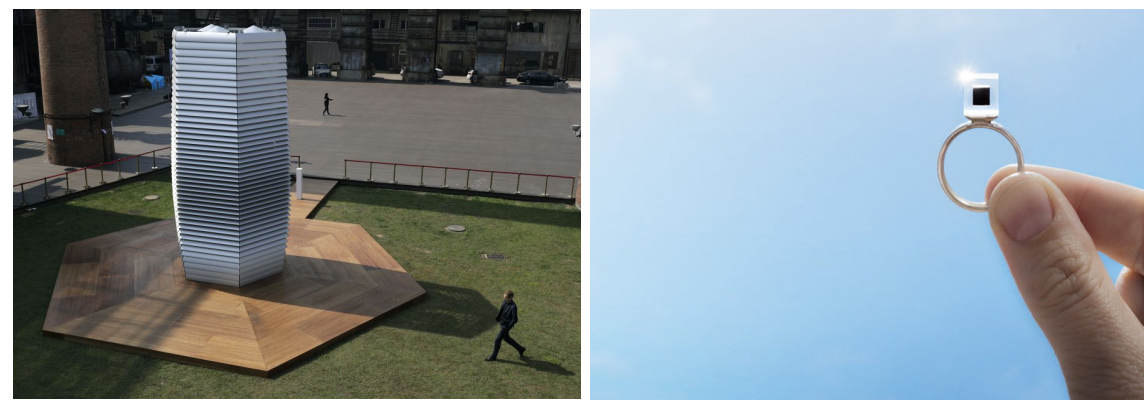

Figure 2. Smog free tower and one type of its produced jewelries [17] [18].

percent cleaner in the park than it is in the surrounding area. Every day, the structure filters and compresses enough smog to form a handful of synthetic cubes. "This [smog] is not waste," Roosegaarde said in a promotional video for the campaign. "Waste in the future should not exist... 42 percent of this [smog] exists as carbon and [with] carbon under high-pressure you get diamonds" [17].

The Smog Free Project is not only intended to be a local solution for parks, but also an inspirational experience of a clean future. Along with governments, NGOs, pro-bicycle campaigns and the clean-tech industry, people can work together to make a whole city smog free. Last year Daan Roosegaarde and his team erected a seven-meter-tall air purifier in Beijing. The massive structure has its roots in a Kickstarter campaign that raised $€ 113,153(\$ 127,000)$ in August 2015. It appeared first in Rotterdam last year before making its way east. With the support from China's Ministry of Environmental Protection, the structure will travel to three additional cities in the country after its stint in Beijing [18].

\subsection{Tvilight Lighting Controls in Nijmegen, Netherlands}

The intelligent lighting solution delivered by Tvilight (Figure 3) is applied on a new city ring road (s100) constructed in Nijmegen, one of the oldest and densely populated cities in the Netherlands, in the year 2013. The road stretches from national the highway through to the heart of the city and is aimed at facilitating a better traffic flow. Within a week of installation, Tvilight lighting controls made the roadway lighting adaptive. The lighting levels now adjust automatically based on the actual traffic conditions. When no presence is detected, the streetlights dim to $20 \%$ of their full-capacity. Such minimum light levels ensure that there is still visibility on the street and thereby assuring the safety and security. When a car approaches, a number of surrounding lights in front of the car glow-up to a brighter level, ensuring that the car is always surrounded by a safe circle of light.

As expected, the city achieves over $60 \%$ in energy savings and an equivalent reduction in the $\mathrm{CO}_{2}$ emissions. Furthermore, the Tvilight system allows remote monitoring, management and control of entire lighting infrastructure through the user-friendly City Manager software [19]. 


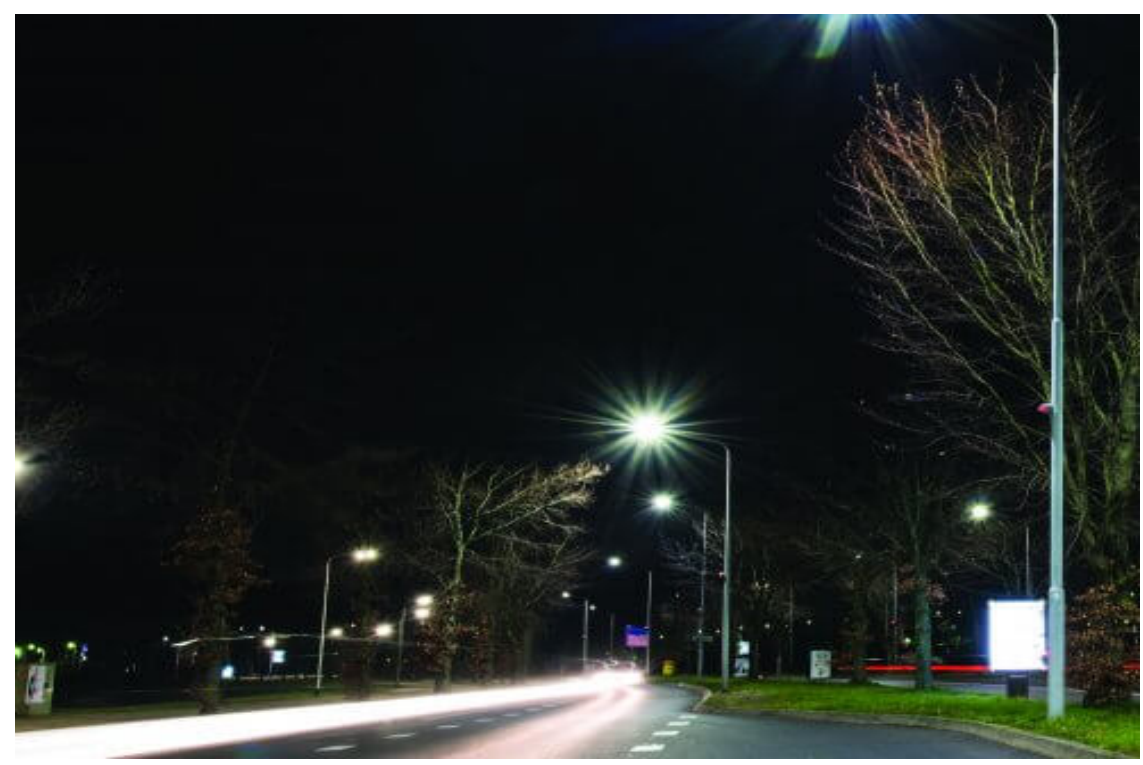

Figure 3. Tvilight lighting controls in Nijmegen [19].

\subsection{PV-Covered Bike Lane Connecting Sejong and Daejeon, South Korea}

Although this is not an urban project but, clearly, it can be used in urban areas too. Korea has created a PV-covered bike lane connecting Sejong and Daejeon (Figure 4), which offers a clean transit option that utilizes unused median space in an existing highway, while providing renewable solar electricity. The PV-covered bike lanes runs approximately 20 miles (32 kilometers) from Sejong to Daejeon [20].

Bicyclists are protected by a guard rail. This innovative use of unused infrastructure is part of a proposed bike path network that will eventually cover more than 217 miles (350 kilometers) around the city of Sejong. According to Gas2, "Korea's crowded highways have convinced many commuters to ditch four wheels and an engine for two wheels and pedals" [20].

\subsection{Pollution Absorptive Billboard in Lima, Peru}

This sort of billboard-located in Lima, Peru (Figure 5) - sucks pollution from the sky and returns purified air to the surrounding areas. Not just trace amounts of air, but 100,000 cubic meters of urban air per day. That's over 3.5 million cubic feet, which University of Engineering and Technology of Peru says is equivalent to the work of 1200 mature trees. That's a lot of air. Furthermore, UTEC claims the billboard is "totally effective in removing [the] dust, metal and stone particles" that contaminate air spaces around construction zones, and which can lead to life-threatening health problems, from respiratory issues to cancer. The university describes the billboard working progress as "a highly efficient continuous process, with very low energy consumption"-just 2.5 kilowatts (2500 watts) of electricity per hour, or roughly what an emergency generator might consume powering your bare essentials in a small home [21]. 


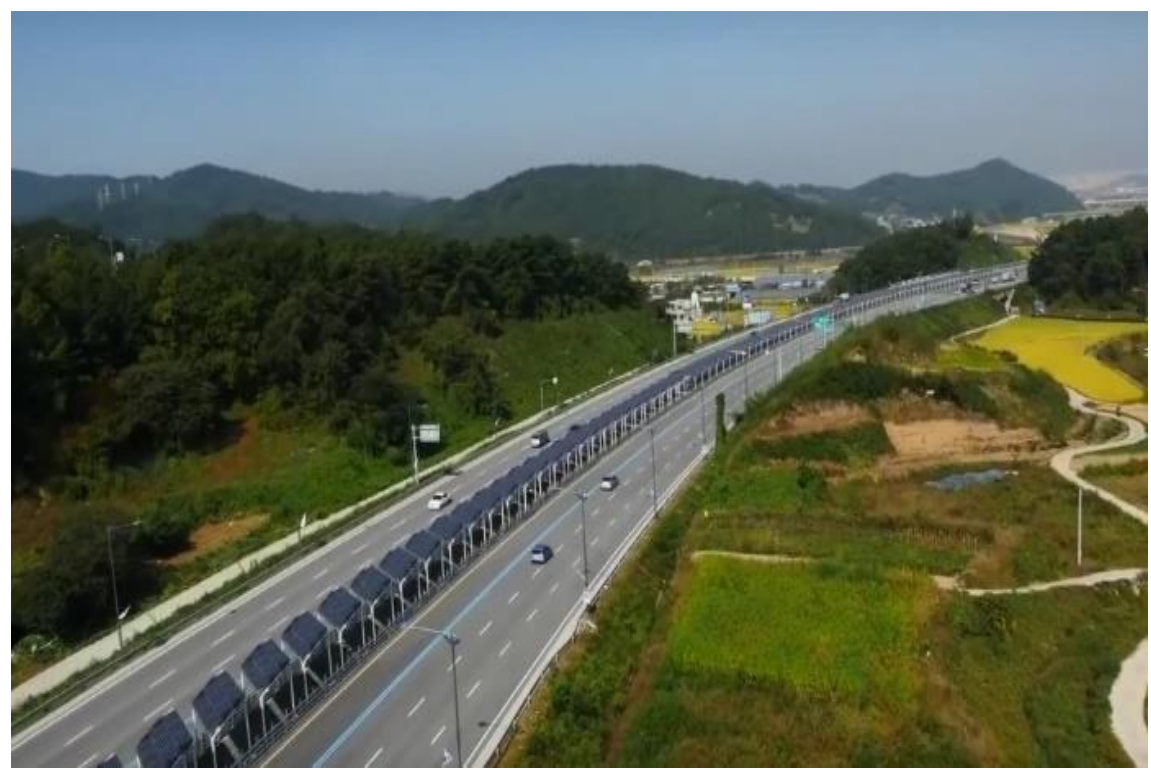

Figure 4. PV-covered bike lane connecting Sejong and Daejeon [20].

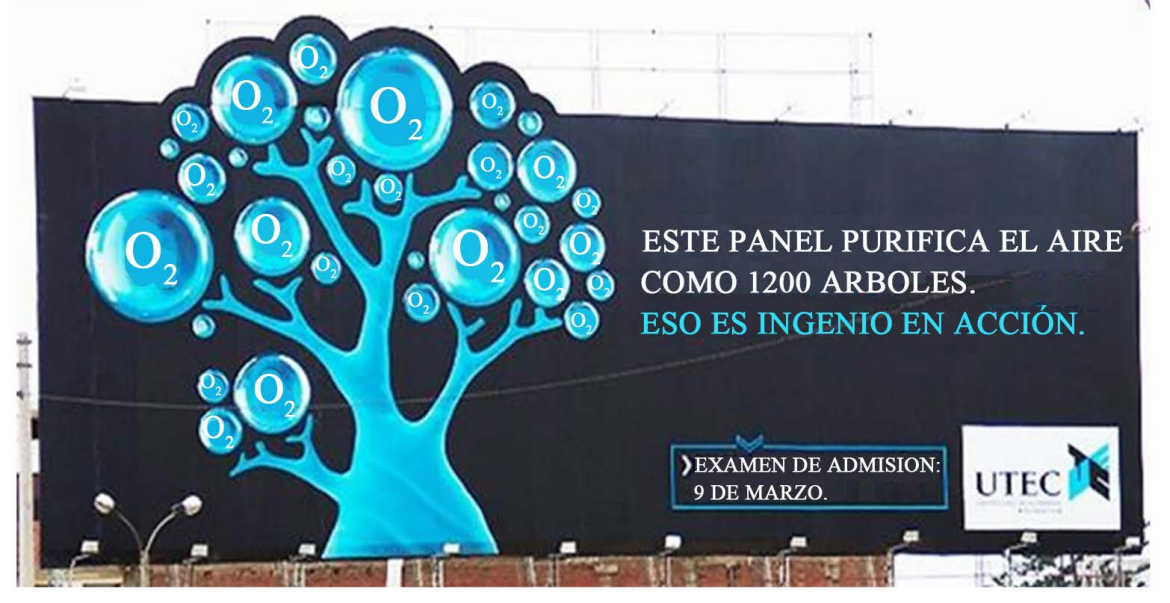

Figure 5. Pollution absorptive billboard in Lima, Peru [21].

\section{Solutions of a Proper Technological Design in Urban Space}

With studying the importance of the technology, as one of four constituent elements of architecture and the need for the presence of technology in today conditions, it is necessary to have some implementations to guide the designers and managers to have proper designs and decisions. The following notes are suggested by this paper in order to propose some steps to achieve more appropriate designs and planning.

- Displaying technology as the essence and the achievement of used elements in the new era of designing spaces.

- Clarifying, layering and displaying of motion in spaces using up-to-date materials and constructions.

- Using bright and simple colors to reach sustainability in terms of beauty. 
- Using structures and constructions as architecture decorations (structural materials should be accepted as both functional and aesthetic elements).

- Choosing Functional materials due to structural and climatic issues

- Using lightweight and flexible components to change the view of spaces if required.

- Separating the service provider parts and the parts which are serviced.

- Creating Walkable Urbanism.

- Supporting Transit-oriented development.

- Supporting Green Transportation Planning.

- Integrating traditional creative and technical skills with an up-to-date understanding of environmental, social and economic impacts.

- Applying the Standards for reducing energy and $\mathrm{CO}_{2}$ emissions in buildings and urban spaces.

- Having Environmental Assessment Methodology in all urban projects.

- Monitoring of combustion gasses and preemptive fire conditions to define alert zones.

- Controlling $\mathrm{CO}_{2}$ and toxic gas emissions from factories, farms and cars.

- Monitoring of soil moisture, vibrations and earth density to detect land conditions.

\section{Conclusion}

Architecture and technology have a long relationship; during the time, technological terms and solutions have been always used by architects and urbanists to create numerous masterpieces and also to improve the living environment of people in societies. In the technological design, what is visible at first view, is eco-friendliness and saving energy, which puts it among the human excellent developments. Technological design has been identical effective in urban development; quality increasing of materials, saving energy and consequently sustainable architecture and environmental sustainability can be mentioned as some of its advantages. Aesthetical aspects and human comfort circumstances are also two important factors that can be achieved by using technology in design procedure. By doing this descriptive-analytic study, with library research method which is used for data collecting, some implementations are suggested to improve the urban situations by using technological solutions.

\section{References}

[1] Fakouhi, N. (2008) Urban Anthropology. Nashreney, Tehran.

[2] Arnheim, R. (1977) The Dynamics of Architectural form: Based on the 1975 Mary Duke Biddle lectures at the Cooper Union (Vol. 376). University of California Press.

[3] Grütter, J.K. (1987) Ästhetik der Architektur Grundlagen der Architektur-Wahrnehmung. [Aesthetics of Architecture: The Foundations of Architectural Perception].

[4] Norberg-Schulz, C. (1980) Genius Loci: Towards a Phenomenology of Architecture. Rizzoli. 
[5] Masoomi Ashkoori, S.H. (2004) Principles and Basics of Regional Planning. Payam Publications, Tehran.

[6] Habibi, S.M. and Maghsoudi, M. (2007) Urban Restoration. Tehran University Publisher, Tehran.

[7] Salehi, E. (2008) Environmental Features of Safe Urban Areas. Study and Research Center of Urbanism and Architecture. Tehran.

[8] Khodadad, M. and Sanei, M. (2016) Suggested Solutions to Improve Security in Urban Environment with an Approach of Sustainable Development. Proceedings of the 4th International Congress on Civil Engineering, Architecture and Urban Development, Shahid Beheshti University, Tehran, 27-29 December 2016.

[9] Bagheri Beheshti, Sh. (2006) Public Realms, Forgotten Realms in New Cities. Proceedings of International Conference of New Towns, Tehran, 4-8 May 2006.

[10] Krier, R. and Rowe, C. (1979) Urban Space. Academy Editions, London.

[11] Habibi, S.M. (2000) Urban Space: A Theoretical Confrontation. Soffeh, 33.

[12] Asadi, M.R. and Mousavi Mehr, M.M. (2010) The Nature of Technology in Heidegger's Philosophy. Wisdom and Philosophy, 6, 49-69.

[13] Sanei, M., Khodadad, M. and Ghadim, F.P. (2017) Effective Instructions in Design Process of Urban Public Spaces to Promote Sustainable Development. World Journal of Engineering and Technology, 5, 241-253.

[14] Golabchi, M. and Shahroudi, A. (2007) Introduction to Technology and Architecture. National Trust Newspaper, Tehran, 510.

[15] Cresswell, J. (2010) Oxford Dictionary of Word Origins. 2nd Edition, Oxford University Press Ink., New York.

[16] Reddy, N.M. and Zhao, L. (1990) International Technology Transfer: A Review. Research Policy, 19, 285-307.

[17] Furness, D. (2016) Beijing's Silver-Plated “Smog Free Tower” Turns Pollution into Carbon Cubes. http://www.digitaltrends.com/cool-tech/smog-free-tower-beijing

[18] Horwitz, J. (2016) An Air Purifier the Size of a Building Is Sucking Up China's Smog and Turning It into Jewelry.

https://qz.com/796945/smog-free-tower-an-air-purifier-the-size-of-a-building-is-su cking-up-chinas-pollution-and-turning-it-into-jewelry/

[19] Intelligent Roadway Lighting: Energy Savings through Dynamic Dimming on the S100 in Nijmegen (2016). https://www.tvilight.com/2016/10/18/case-study-public-roadways/

[20] Meyers, G. (2015) South Korea Launches PV-Covered Bike Lane for Unused Infrastructure.

https://cleantechnica.com/2015/04/21/south-korea-launches-pv-covered-bike-laneunused-infrastructure/

[21] Peckham, M. (2014) This Billboard Sucks Pollution from the Sky and Returns Purified Air.

http://time.com/84013/this-billboard-sucks-pollution-from-the-sky-and-returns-pu rified-air/ 